\title{
The Influence of Extreme Climate Events on Models of Coral Colony Recruitment and Survival in the Caribbean
}

\author{
Michael James C. Crabbe \\ Institute of Biomedical and Environmental Science \& Technology, \\ Faculty of Creative Arts, Technologies and Science, University of Bedfordshire, Luton, U.K. \\ Email: james.crabbe@beds.ac.uk
}

Received February 15, 2012; revised March 6, 2012; accepted March 15, 2012

\begin{abstract}
Knowledge of coral recruitment patterns helps us understand how reefs react following major disturbances and provides us with an early warning system for predicting future reef health problems. We have reconstructed and interpreted historical and modern-day recruitment patterns, using growth modeling, in order to understand how hurricanes, storms and bleaching events have influenced coral recruitment in the Caribbean. The results indicate that regional hurricane events negatively impact coral recruitment patterns in the Caribbean, from the south in Tobago to more northerly areas in Belize and Jamaica. However, despite multiple large-scale disturbances, corals are still recruiting to marginal reef systems, and to the Mesoamerican Barrier reef off the coast of Belize. While recruitment and initial growth since the Caribbean-wide bleaching event of 2005 has been successful for Colpophylia natans at the sites studied in North Jamaica, medium and large sized colonies of this species have decreased in numbers since the bleaching event at most sites, except where the rugosity is highest, at Dairy Bull reef.
\end{abstract}

Keywords: Demographics; Tropical Storms; Hurricanes; Cyclones; Bleaching; Climate Change; Global Warming; Coral Growth

\section{Introduction}

Loss of corals and macroalgal domination in many parts of the Caribbean has been due to hurricanes [1-2], overfishing [3-4], die-off of the long-spined sea urchin Diadema antillarum in 1983-84 [5], and coral disease [6]. Decline in architectural complexity of Caribbean reefs has been apparent since the 1980s, and coincide with key events in recent Caribbean ecological history [7-8]. The major acute climate disturbance in recent years was the Caribbean-wide bleaching event of 2005 [9]. This event was due primarily to high sea surface temperature (SST) hot-spots in the region [10], and thermal stress during this event exceeded any seen in the previous 20 years of satellite data from the Caribbean, while monthly temperatures were the warmest in over 150 years.

Maintaining coral reef populations in the face of largescale degradations due to climate or other environmental effects is a key aspect of reef resilience. Factors that can improve coral reef resilience include successful recruitment, species and functional diversity, connectivity to larval sources, appropriate substrates for larval settlement, and protection from other anthropogenic effects [11-13]. Rugosity, the three-dimensional topography of reefs, has been linked to reef resilience in the South Central Pacific [14], and has been selected as a bioindicator for use in monitoring programmes linking changes in water quality to changes in the condition of coral reef ecosystems [15]. Reef rugosity, a measure of small-scale variations in the height of the substrate on the sea bed, due to scleractinian corals, correlates well with rocky reef fish community structure in Brazil [16], Hawaii [17], the Great Barrier Reef [18], Barbados [19], the Seychelles [20], and the Gulf of Mexico [21]. Rugose locations aid aggregation of Diadema antillarum urchins, important to keep macroalgae in check [22].

Here we wished to test the hypothesis that hurricanes and tropical storms limit the recruitment and subsequent survival of massive non-branching corals at four sites in the Caribbean; the north and south coats of Jamaica, the meso-American Barrier Reef off the coast of Belize, and the coastal reefs of Tobago. In addition, we studied the population size-structure of corals on the North Coast of Jamaica from 2002-2008, and tested whether rugosity was a factor in the changes in colony numbers of small and of medium-large sized colonies after the mass bleaching event of 2005.

\section{Materials and methods}

\subsection{Reef Sites}

For North Jamaica, five sites (Rio Bueno, M1, Dancing 
Ladies, Dairy Bull and Pear Tree Bottom) were selected along the fringing reefs surrounding Discovery Bay as described previously [23]. This work was conducted at Discovery Bay during March 26-April 19 in 2002, March 18-April 10 in 2003, July 23-August 21 in 2004, July 18-August 13 in 2005, April 11-18 in 2006, December 30 in 2006-January 6 in 2007, and July 30-August 16 in 2008 and July 27-August 8 in 2009. Surveys were made at the same locations and the same sites each year. For GPS co-ordinates and species see [23].

For South Jamaica, surface areas of non-branching corals selected haphazardly were measured at seven sites (Lime Cay, Gun Cay, Drunkenman’s Cay, Rackham’s Cay, Maiden Cay and Edina wreck) south of Port Royal, near Kingston Harbour as described [24]. This work was conducted in April 2010. For GPS co-ordinates and species see [23,24].

For Belize, sites were selected as described previously [25] in the Sapodilla Cayes Marine Reserve (six sites: Mantas garden, Franks I, Franks II, Nicholas Cay, Protected I site and Seal Cay) and the Port Honduras Marine Reserve (two sites: South snake Cay and Barracuda Bank). The work was carried out in July and August 2006, and in August 2007. For GPS co-ordinates and species see [25].

For Tobago, six sites (Kariwak, Buccoo, Mt. Irvine, Culloden, Little Englishman's Bay and Sisters) were selected along the Caribbean coast of the island, as described previously [26]. The work was done in May and October 2008. For GPS co-ordinates and species see [26].

\subsection{Sampling}

Details of data sampling have been described for North Jamaica and South Jamaica [23], Belize [25] and Tobago [26]. In summary, corals $2 \mathrm{~m}$ either side of transect lines were photographed for archive information, and surface areas measured with flexible tape as described previously using SCUBA. For non-branching corals, this was done by measuring the widest diameter of the coral and the diameter at $90^{\circ}$ to that. To increase accuracy, surface areas rather than diameters of live non-branching corals were measured [2]. Sampling was over as wide a range of sizes as possible. Colonies that were close together $(<50 \mathrm{~mm})$ or touching were avoided to minimise age discontinuities through fission and altered growth rates $[27,28]$.

One or two-factor ANOVA was used to compare coral data among sites; \pm error values represent standard errors of the data. The year of an individual's recruitment was calculated from a knowledge of the growth rate (e.g. 3.25 $\mathrm{mm} / \mathrm{yr}$ for Porites astreoides, $3 \mathrm{~mm} / \mathrm{yr}$ for Siderastrea siderea) [29-31], taken from sites in the Caribbean at similar depths and visibility to those encountered here, the majority from [30]. For example, a Porites astreiodes colony of measured elliptical surface area $51.8 \mathrm{~cm}^{2}$ was estimated to have recruited (and survived) 23 years ago.

\subsection{Rugosity}

Rugosity $(R)$, the measure of small-scale variations or amplitude in the height of the substrate on the sea bed, due to scleractinian corals, was determined according to the formula:

$$
R=S r / S g
$$

where $S r=$ real surface distance between two points, taking into account only scleractinian corals, and $S g=$ straight line geometric distance between two points. This was calculated over a $20 \mathrm{~m}$ distance, performed in triplicate, at each site, using photographic image analysis verified by the chain method, similar to those used on reefs previously [32-35].

\subsection{Data on Storms, Hurricanes and Bleaching Events}

Data on storm severity as it impacted the Caribbean sites was obtained from UNISYS

(http://weather.unisys.com/ hurricane/atlantic/)

the NOAA hurricane site

(http://www. nhc.noaa.gov/pastall.shtml).

Information on bleaching was obtained from the NOAA coral reef watch site:

(http: //coralreefwatch.noaa.gov/satellite/current/sst_series _24r eefs.html)

and from [36].

\section{Results}

We identified hurricane and bleaching events which were reported to have had an impact in recent years on Jamaica's reefs, these included: major coral bleaching (2005), Hurricanes Charley and Ivan (2004), Hurricanes Emily and Dennis (2005), and Hurricane Dean (2007). In earlier decades, Hurricanes Allen (1980) and Gilbert (1988) were particularly damaging to the island.

Figure 1 shows that for all the sites studied in Jamaica, Belize and Tobago, there were significant differences in non-branching coral recruitment in years when hurricanes impacted the areas of those sites. For each site, the differences were significant at $\mathrm{p}=0.016$ (Tobago [354]), $\mathrm{p}=0.019$ (Belize [523]), $\mathrm{p}=0.04$ (North coast Jamaica [1560]) and $p=0.007$ (South coast Jamaica [347]). Numbers in square brackets refer to the numbers of non-branching corals measured at each site.

Figure 2 shows the size-frequency distribution of the coral Diploria strigosa at the fringing reef sites Rio Bueno, M1, Dancing Ladies, Dairy Bull and Pear Tree Bottom on the North coast of Jamaica in 2002 (Figure 2(a)) and 2008 (Figure 2(b)). These dates cover the major bleaching event in 2005 and the major hurricane to hit the area during that time, Hurricane Ivan in 2004. 


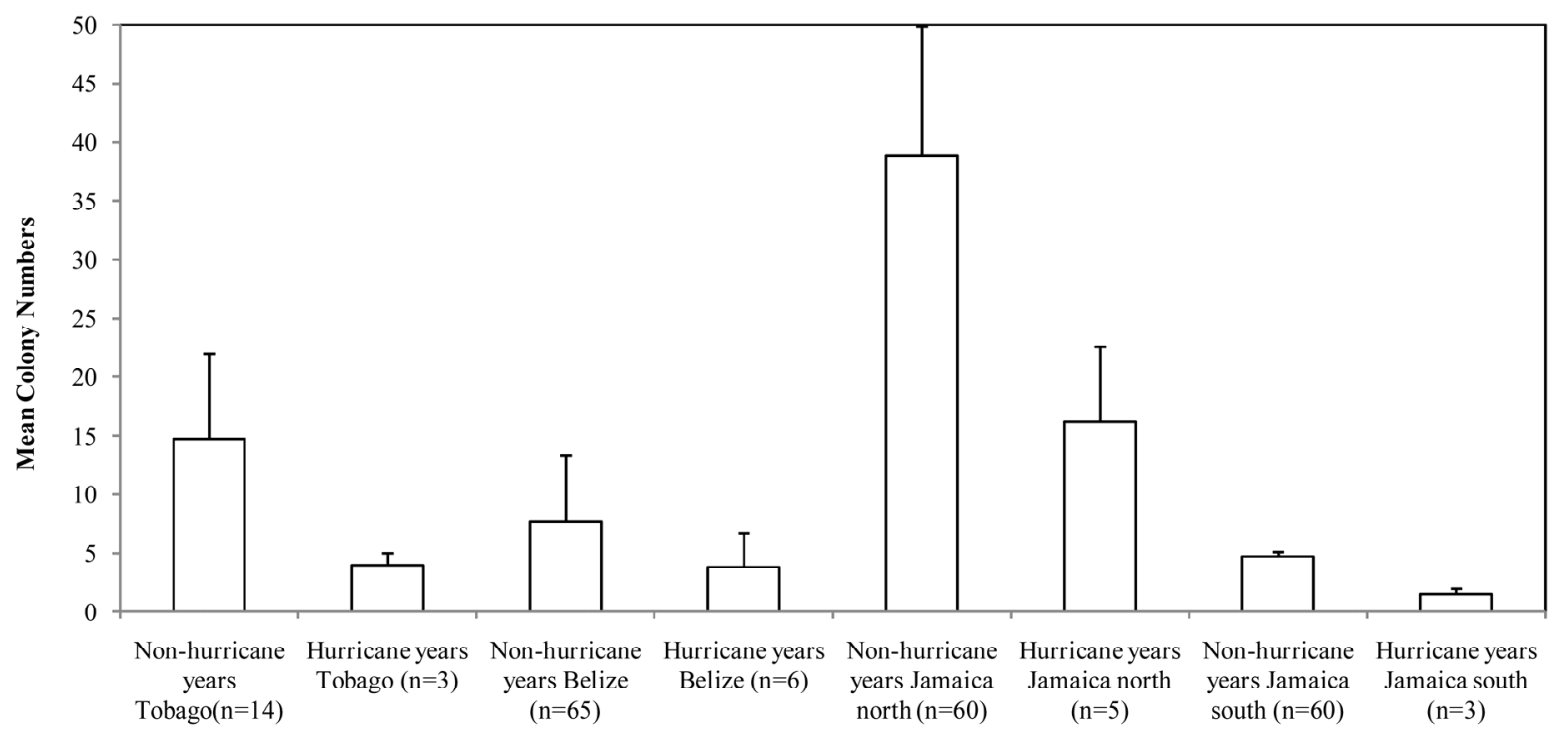

Figure 1. Mean number ( \pm 1 s.d.) of coral colonies recruiting at sites in the Caribbean in hurricane years, and in years when there were no hurricanes. $N$ refers to the number of years for each sample.

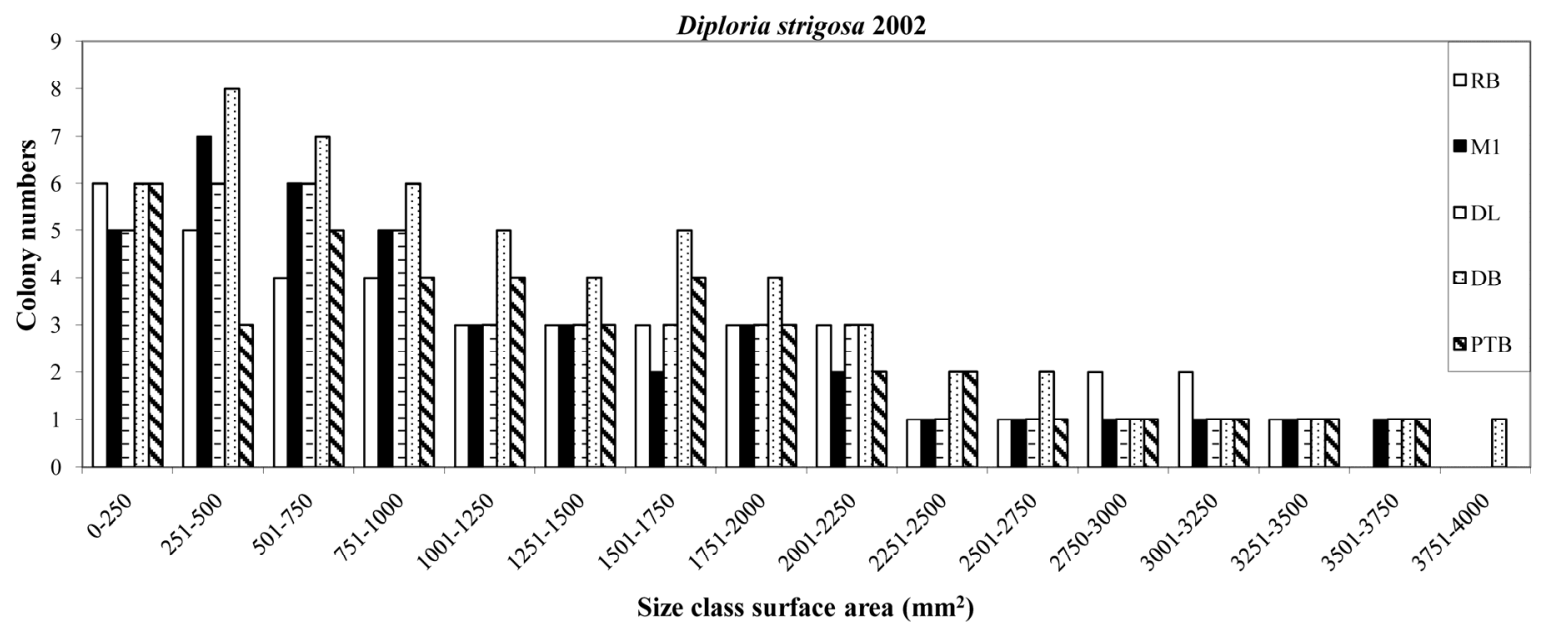

(a)

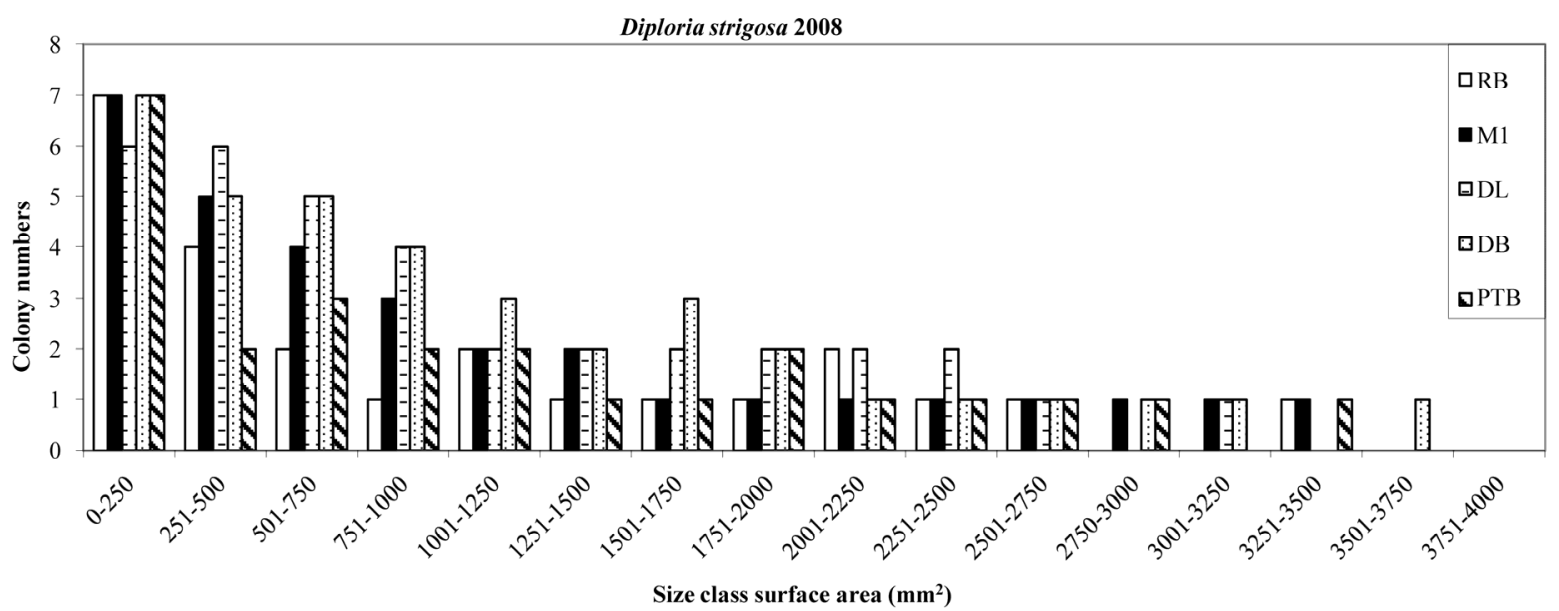

(b)

Figure 2. Size-frequency distribution of the coral Diploriastrigosa at the fringing reef sites Rio Bueno (RB), M1 (m1), Dancing Ladies (DL), Dairy Bull (DB) and Pear Tree Bottom (PTB) on the North coast of Jamaica in 2002 (Figure 2(a)) and 2008 Figure 2(b)). 
Rugosities were calculated for each site on the North coast of Jamaica: Rio Bueno, $1.05 \pm 0.15$; M1, $1.17 \pm$ 0.12; Dancing Ladies, $1.3 \pm 0.15$; Dairy Bull, $2.3 \pm 0.16$ and Pear Tree Bottom, $1.23 \pm 0.11$. Figure 3 shows that there were significant relationships between mean rugosity values at these sites and changes in both small $(<250$ $\mathrm{mm}^{2}$ ) and medium-large sized (>250 $\mathrm{mm}^{2}$ ) Colpophyllia natans colony numbers from $2006-2009$. $\mathrm{R}^{2}$ values were 0.77 for colonies $<250 \mathrm{~mm}^{2}$ and 0.91 for colonies $>250$ $\mathrm{mm}^{2}$.From 2006-2009, after the mass bleaching event of 2005, there was an increase in small colony numbers, with a greater increase at sites with high rugosity. For medium-large sized colonies, there was a decrease in colony numbers from 2006-2009 at sites where the rugosity was $<1.8$. Only at Dairy Bull, where the rugosity was 2.3, did medium-large sized $C$. natans numbers increase between 2006 and 2009.

\section{Discussion}

Our studies indicate that recruitment of non-branching corals on both fringing and barrier reefs in the Caribbean declined significantly in years following hurricanes and storms. While this study did not measure recruitment directly, settlement plates experiments in Tobago gave results that agreed with modelling studies [26]. Jamaican non-branching coral recruitment on the North coast took 1-2 years to return to pre-hurricane levels [2], a much more rapid recovery than seen on Tobago's reefs following the combined effects of Hurricane Ivan and coral bleaching
[26]. This could be because there were significantly more degree heating weeks experienced by the reefs of Tobago than of North Jamaica [9]. In Belize, in 1998 coral populations simultaneously experienced a severe coral bleaching event and Hurricane Mitch. A study of coral recruits [37] found that whilst bleaching alone had no effect on recruitment density or community structure, the combined effects resulted in a $20 \%$ reduction of pre-disturbance levels. Sixty-six percent of Tobago's coral colonies suffered from bleaching, with an estimated 73\% mortality of C. natans and Diploria species [38]. In recruitment studies on Tobago, Diploria species dominated the limited number of recruits observed from 2004 to 2006, with some $C$. natans also recruiting in 2006, indicating low levels of recovery for these framework-building species [26]. While occasional storms can increase the survivorship of branching Acropora palmata colonies [39], storminduced decrease in reef rugosity can limit the settlement of coral planulae, as survival is greater in the shade or under surfaces [40].

Measurements of size-frequency distribution are useful in evaluating the condition of and changes in coral populations caused by acute and chronic disturbances [41-43]. Despite the multiple influences on the reef sites of North Jamaica over the study period, the size classes of $D$. strigosa showed some resilience to change, not least in colony numbers of the smallest size class. This behaviour of $D$. strigosa was similar to distribution of other nonbranching species, particularly $P$. astreoides [44].

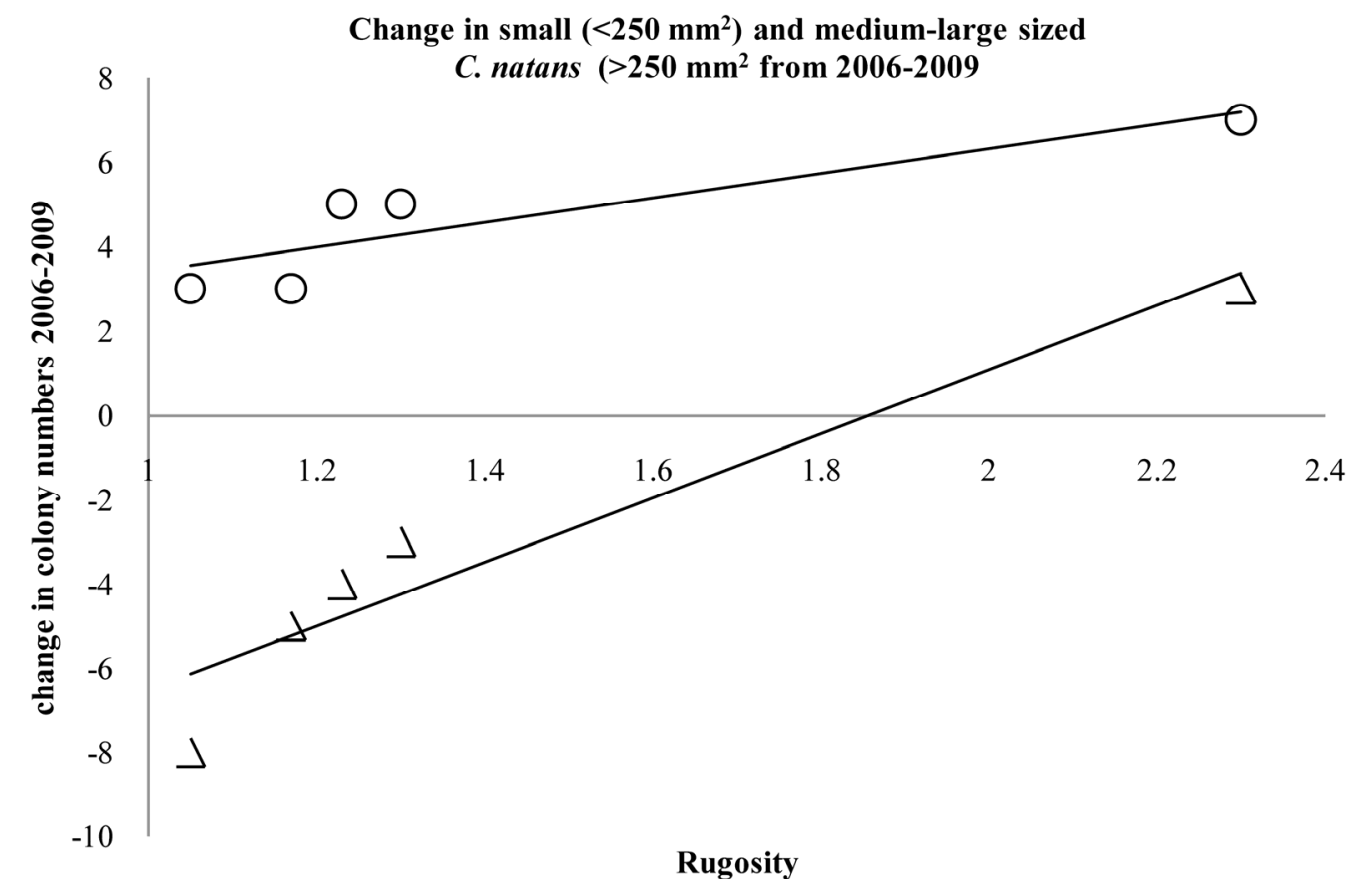

Figure 3. Relationships between mean rugosity values at sites on the North coast of Jamaica near Discovery Bay and changes in both small $(0)\left(<250 \mathrm{~mm}^{2}\right)$ and medium-large sized $(\Delta)\left(>250 \mathrm{~mm}^{2}\right)$ Colpophyllia natans colony numbers from $2006-2009$. $R^{2}$ values were 0.77 for colonies $<250 \mathrm{~mm}^{2}$ and 0.91 for colonies $>250 \mathrm{~mm}^{2}$. 
Reef rugosity, contact of corals with macroalgae, and aggregation and competition between corals can influence reef resilience together with species and functional diversity, connectivity to larval sources, appropriate substrates for larval settlement, and protection from other anthropogenic effects [11,12].As reefs become increasingly subjected to high sea surface temperatures and thermal stress [45], it is important for reef managers to consider all these factors to ensure coral resilience to continued environmental stressors. We have shown that rugosity positively correlates with coral cover of Acropora cervicornis colonies [46]. Increase in A. cervicornis cover was one of the main reasons for suggesting a phase-shift reversal at Dairy Bull reef [47].

The continued presence of small coral colonies over time can indicate reef resilience $[48,49]$, and here we demonstrate that increases in colony numbers of both the smallest size class $\left(<250 \mathrm{~mm}^{2}\right)$ and the medium-large size class $\left(>250 \mathrm{~mm}^{2}\right)$ for $C$. natans are significantly correlated with reef rugosity at all the sites studied around Discovery Bay on the North coast of Jamaica since the mass bleaching event of 2005. The major difference between the size classes is that where the rugosity is $<1.8$, i.e. for most of the sites studied, there is a decrease in colony numbers of the medium-large sized $C$. natans. This suggests that while recruitment and initial growth since 2005 has been successful for this species at the sites studied in North Jamaica, medium and large sized colonies of this species have decreased in numbers since the bleaching event at most sites, except where the rugosity is highest, at Dairy Bull reef. At Dairy Bull, the bleaching event in 2005 led to significant loss of coral cover [44], which allowed space for the development of new colonies. Water quality is not a factor in differences between the reef sites [50].

These findings suggest that the three dimensional topography and complexity is important for reef resilience and viability in the face of extreme environmental stressors. Interestingly, rugosity also correlates well with fish abundance on other reefs, for example with parrotfish (Scarid) abundance on reefs of Oahu, Hawaii [51], and rugosity has been used in regional modelling of coral habitats for marine conservation [52].

Reefs are under stress from a variety of insults that act in synergy [53]. It may be that under conditions of low coral cover, low reef rugosity and low biodiversity, a major disturbance such as the 2005 bleaching event crosses a 'threshold' which then induces a cascade to induce the crossing of other thresholds, leading to a stable but less desirable alternative state [54]. An example where this has happened may be the reefs of Tobago [26]. On the reefs of North Jamaica, there is a variable response and resilience, strongest in the case of Dairy Bull reef, which exhibits relatively high rugosity, coral cover and biodiversity with no significant macroalgal cover [46].Whether the niche diversification and multiple symbiont clades in corals at Dairy Bull Reef is sufficient to allow for adaptive radiation [55] in a period of intense climate change and ocean acidification is yet to be resolved.

\section{Acknowledgements}

I am indebted to Dr. J. Mallela for her work on the coral reefs of Tobago. I thank Mr. Anthony Downes, Mr. Peter Gayle, and the staff of the Discovery Bay Marine Laboratory for their invaluable help and assistance, and to many volunteers for their considerable help underwater during this project, I am also indebted to Mr.Camilo Trench and colleagues at Port Royal Marine Station, Jamaica for their invaluable assistance in data collection, and staff of the University of the West Indies, Mona campus, for their logistical help. I thank the Royal Society and the Earthwatch Institute for funding parts of this study. I would also like to thank Ms. Marcia Creary, University of the West Indies, for helpful conversations.

\section{REFERENCES}

[1] J. D. Woodley, E. A. Chornesky, P. A. Clifford, J. B. C. Jackson, L. S. Kaufman, N. Knowlton, J. C. Lang, M. P. Pearson, J. W. Porter, M. C. Rooney, K. W. Rylaarsdam, V. J. Tunnicliffe, C. M. Wahle, J. L. Wulff, A. S. G. Curtis, M. D. Dallmeyer, B. P. Jupp, M. A. R. Koehl, J. Neigel and E. M. Sides, "Hurricane Allen's Impact on Jamaican Coral Reefs,” Science, Vol. 214, No. 4552, 1981, pp. 749-755. doi:10.1126/Science.214.4522.749

[2] M. J. C. Crabbe, J. M. Mendes and G. F. Warner, "Lack of Recruitment of Non-Branching Corals in Discovery Bay Is linked to Severe Storms," Bulletin of Marine Science, Vol. 70, No. 3, 2002, pp. 939-945.

[3] J. B. C. Jackson, "Reefs since Columbus," Coral Reefs, Vol. 16, 1997, pp. 97-106.

[4] J. P. Hawkins and C. M. Roberts, "Effects of Artisanal Fishing on Caribbean Coral Reefs,” Conservation Biology, Vol. 18, No. 1, 2004, pp. 215-226.

[5] T. P. Hughes, "Catastrophes, Phase Shifts and LargeScale Degradation of a Caribbean Coral Reef," Science, Vol. 265, No. 5178, 1994, pp. 1547-1551. doi:10.1126/Science.265.5178.1547

[6] R. B. Aronson and W. F. Precht, "Evolutionary Paleoecology of Caribbean Coral Reefs,” In: W. D. Allmon and D. J. Bottjer, Eds., Evolutionary Paleoecology: The Ecological Context of Macroevolutionary Change, Columbia University Press, New York, 2001, pp. 171-233.

[7] L. Alvarez-Filip, N. K. Dulvy, J. A. Gill, I. M. Côté and A. R. Watkinson, "Flattening of Caribbean Coral Reefs: Region-Wide Declines in Architectural Complexity," Proceeding of the Royal Society of London B, Vol. 276, 2009, pp. 3019-3025.

[8] L. Alvarez-Filip, J. A. Gill, N. K. Dulvy, A. L. Perry, A. 
R. Watkinson and I. M. Coté, "Drivers of Region-Wide Declines in Architectural Complexity on Caribbean Reefs,” Coral Reefs, Vol. 30, 2011, pp. 1051-1060. doi:10.1007/s00338-011-0795-6

[9] C. M. Eakin, J. A. Morgan, S. F. Heron, T. B. Smith, G. Liu, L. Alvarez-Filip, B. Baca, E. Bartels, C. Bastidas, C. Bouchon, M. Brandt, A. W. Bruckner, L. Bunkley-Williams, A. Cameron, B. D. Causey, M. Chiappone, T. R. L. Christensen, M. J. C. Crabbe, O. Day, E. de la Guardia, G. Díaz-Pulido, D. DiResta, D. L. Gil-Agudelo, D. S. Gilliam, R. N. Ginsburg, S. Gore, H. M. Guzmán, J. C. Hendee, E. A. Hernández-Delgado, E. Husain, C. F. G. Jeffrey, R. J. Jones, E. Jordán-Dahlgren, L. S. Kaufman, D. I. Kline, P. A. Kramer, J. C. Lang, D. Lirman, J. Mallela, C. Manfrino, J.-P. Maréchal, K. Marks, J. Mihaly, W. J. Miller, E. M. Mueller, E. Muller, C. A. Orozco Toro, H. A. Oxenford, D. Ponce-Taylor, N. Quinn, K. B. Ritchie, S. Rodríguez, A. Rodríguez Ramírez, S. Romano, J. F. Samhouri, J. A. Sánchez, G. P. Schmahl, B. V. Shank, W. J. Skirving, S. C. C. Steiner, E. Villamizar, S. M. Walsh, C. Walter, E. Weil, E. H. Williams, K. Woody Roberson and Y. Yusuf, "Caribbean Corals in Crisis: Record Thermal Stress, Bleaching, and Mortality in 2005,” PLOS ONE, Vol. 5, No. 11, 2010, p. e13969. doi:10.1371/journal.pone.0013969

[10] D. Abrego, K. E. Ulstrup, B. L. Willis and M. J. H. van Oppen, "Species-Specific Interactions between Algal Endosymbionts and Coral Hosts Define Their Bleaching Response to Heat and Light Stress,” Proceedings of the Royal Society B, Vol. 275, No. 1648, 2008, pp. 22732282.

[11] M. Nyström, N. A. J. Graham, J. Lokrantz and A. V. Norström, "Capturing the Cornerstones or Coral Reef Resilience: Linking Theory to Practice,” Coral Reefs, Vol. 27, No. 4, 2008, pp. 795-809. doi:10.1007/s003338-0086-0426-z

[12] A. R. Halford and M. J. Caley, "Towards an Understanding of Resilience in Isolated Coral Reefs,” Global Change Biology, Vol. 15, No. 12, 2009, pp. 3031-3045. doi:10.1111/j.1365-2486.2009.01972x

[13] D. L. Santavy, E. M. Mieller, L. MacLaughlin, E. C. Peters, R. L. Quarles and M. G. Barron, "Resiliency of Florida Keys Coral Communities Following Large Scale Disturbances,” Diversity, Vol. 3, No. 3, 2011, pp. 628640. doi:10.3390/d3040628

[14] M. Adjeroud, F. Michonneau, P. J. Edmunds, Y. Chancerelle, T. L. de Loma, L. Penin, L. Thibaut, J. Vidal-Dupiol, B.Salvat and R. Galzin, "Recurrent Disturbances, Recovery Trajectories, and Resilience of Coral Assemblages on a South Central Pacific Reef,” Coral Reefs, Vol. 28, 2009, pp. 775-780. doi:10.1007/s00338-009-0515-7

[15] T. F. Cooper, J. P. Gilmour and K. E. Fabricius, "Bioindicators of Changes in Water Quality on Coral Reefs: Review and Recommendations for Monitoring Prgrammes,” Coral Reefs, Vol. 28, No. 3, 2009, pp. 589-606. doi:10.1007/s00338-009-0512x

[16] L. C. L. de Chaves and C. Monteiro-Neto, "Comparative Analysis of Rocky Reef Fish Community Structure in Coastal Islands of South-Eastern Brazil," Journal of Marine Biological Association of the United Kingdom, Vol.
89, No. 3, 2009, pp. 609-619. doi:10.1017/S0025315408002695

[17] K. G. Howard, B. D. Schumacher and J. D. Parrish, "Community Structure and Habitat Associations of Parrotfishes on Oahu, Hawaii," Environmental Biology of Fishes, Vol. 85, No. 2, 2009, pp. 175-186. doi:10.1007/s10641-009-9478-3

[18] M. J. Emslie, A. J. Cheal, H. Sweatman and S. Delean, "Recovery from Disturbance of Coral and Reef Fish Communities on the Great Barrier Reef, Australia,” Marine Ecology Progress Series, Vol. 371, No. 196, 2008, pp. 177-190. doi:10.3354/meps07657

[19] M. R. Chapman and D. I. Kramer, "Gradients in Coral Reef Fish Density and Size across the Barbados Marine Reserve Boundary: Effects of Reserve Protection and Habitat Characteristics,” Marine Ecology Progress Series, Vol. 181, 1999, pp. 81-96. doi:10.3354/meps181081

[20] S. K. Wilson, N. A. J. Graham and N. V. C. Polunin, “Appraisal of Visual Assessments of Habitat Complexity and Benthic Composition on Coral Reefs,” Marine Biology, Vol. 151, No. 3, 2007, pp. 1069-1076. doi:10.1007/s00227-006-0538-3

[21] J. R. Rooker, Q. R. Dokken, C. V. Pattengilland and G. J. Holt, "Fish Assemblages on Artificial and Natural Reefs in the Flower Garden Banks National Marine Sanctuary, USA,” Coral Reefs, Vol. 16, No. 2, 1997, pp. 83-92. doi:10.1007/S003380050062

[22] S. Macia, M. P. Robinson and A. Nalevanko, "Experimental Dispersal of Recovering Diadema Antillarum Increases Grazing Intensity and Reduces Macroalgal Abundance on a Coral Reef," Marine Ecology Progress Series, Vol. 348, 2007, pp. 173-182. doi:10.3354/meps06962

[23] M. J. C. Crabbe, "Environmental Effects on Coral Growth and Recruitment in the Caribbean," Journal of the Marine Biological Association of the United Kingdom, 2012, pp. 1-6. doi:10.1017/S0025315411001913

[24] M. J. C. Crabbe, "Coral Resilience on the Reefs of Jamaica,” Underwater Technology, Vol. 30, No. 2, 2011, pp. 65-70. doi:10.3723/ut.30.065

[25] M. J. C. Crabbe, E. Martinez, C. Garcia, J. Chub, L. Castro and J. Guy, "Growth Modelling Indicates Hurricanes and Severe Storms Are Linked to Low Coral Recruitment in the Caribbean,” Marine Environmental Research, Vol. 65, No. 4, 2008, pp. 364-368. doi:10.1016/j.marenvres.2007.11.006

[26] J. Mallela and M. J. C. Crabbe, "Hurricanes and Coral Bleaching Linked to Changes in Coral Recruitment in Tobago," Marine Environmental Research, Vol. 68, No. 4, 2009, pp. 158-162. doi:10.1016/j.marenvres.2009.06.001

[27] T. P. Hughes and J. B. C. Jackson, "Do Corals Lie about Their Age? Some Demographic Consequences of Partial Mortality, Fission, and Fusion,” Science, Vol. 209, No. 4457, 1980, pp. 713-715. doi: 10.1126/science.209.4457.713

[28] N. L. Foster, I. B. Baums and P. J. Mumby, "Sexual vs. asexual Reproduction in an Ecosystem Engineer: The Massive Coral Montastrea annularis,” Journal of Animal 
Ecology, Vol. 76, 2007, pp. 384-391. doi: 10.1111/j.1365-2656.2006.01207.x

[29] D. K. Hubbard and D. Scaturo, "Growth rates of 7 Species of Scleractinean Corals from Cane Bay and Salt River, St. Croix, USVI,” Bulletin of Marine Science, Vol. 36, No. 2, 1985, pp. 325-338.

[30] M. Huston, "Variation of Coral Growth Rates with Depth at Discovery Bay, Jamaica,” Coral Reefs, Vol. 4, No. 1, 1985, pp. 19-25. doi: 10.1007/BF00302200

[31] J. P. Carricart-Ganivet, A. U. Beltrán-Torrs, M. Merino and M. A. Ruiz-Zárate, "Skeletal Extension, Density and Calcification Rate of the Reef Building Coral Montastrea annularis (Ellis and Solander) in the Mexican Caribbean,” Bulletin of Marine Science, Vol. 66, No. 1, 2000, pp. 215-224.

[32] D. W. Klumpp and A. D. McKinnon, "Community Structure, Biomass and Productivity of Epilithic Algal Communities on the Great Barrier Reef-Dynamics at Different Spatial Scales,” Marine Ecology Progress Series, Vol. 86, 1992, pp. 77-89. doi: 10.3354/meps086077

[33] J. A. Sanchez, J. M. DiazandS. Zea, “Gorgonian Communities in Two Contrasting Environments on Oceanic Atolls of the Southwestern Caribbean,” Bulletin of Marine Science, Vol. 61, No. 2, 1997, pp. 453-465.

[34] T. R. McClanahan, "Predation and the Distribution and Abundance of Tropical Sea Urchin Populations,” Journal of Experimental Marine Biology and Ecology, Vol. 221, No. 2, 1998, pp. 231-255. doi: 10.1016/S0022-0981(97)00130-5

[35] M. J. C. Crabbe and D. J. Smith, “ Sediment Impacts on Growth Rates of Acropora and Porites Corals from Fringing Reefs of Sulawesi, Indonesia," Coral Reefs, Vol. 24, 2005, pp. 437-441. doi: 10.1007/s00338-005-0004-6

[36] L. Jones, P. M.Alcolado, Y. Cala, D. Cobián, V. Coelho, A. Hernández, R. Jones, J. Mallelaand and C. Manfrino, "The Effects of Coral Bleaching in the Northern Caribbean and Western Atlantic,” In: C. Wilkinsonand and D. Souter, Eds., Status of Caribbean Coral Reefs after Bleaching and Hurricanes in 2005, Global Coral Reef Monitoring Network, and Reef and Rainforest Research Centre, Townsville, 2008, pp. 73-83.

[37] P. J. Mumby, "Bleaching and Hurricane Disturbances to Populations of Coral Recruits in Belize," Marine Ecology Progress Series, Vol. 190, 1999, pp. 27-35.

[38] C. Bouchon, P. Portillo, Y. Bouchon-Navaro, M. Louis, P. Hoetjes, K. De Meyer, D. Macrae, H. Armstrong, V. Datadin, S. Harding, J. Mallela, R. Parkinson, J. van Bochove, S. Wynne, D. Lirman, J. Herlan, A. Baker, L. Collado, S. Nimrod, J. Mitchell, C. Morrall and C. Isaac, "Status of Coral Reefs of the Lesser Antilles: The French West Indies, the Netherlands Antilles, Anguilla, Grenada, Trinidad and Tobago," In: C. Wilkinson, Ed., Status of Coral Reefs of the World 2008, Global Coral Reef Monitoring and Reef and Rainforest Research Centre, Townsville, 2008, pp. 265-279

[39] D. Lirman, "A Simulation Model of the Population Dynamics of the Branching Coral Acropora palmate: Effects of Storm Intensity and Frequency,” Ecological Modelling,
Vol. 161, No. 3, 2003, pp. 169-182. doi: 10.1016/S0304-3800(02)00364-0

[40] C. Birkeland, "The Importance of Rate of Biomass Accumulation in Early Successional Stages of Benthic Communities to the Survival of Coral Recruits," Proceedings of the 3rd International Coral Reef Symposium, Miami, May 1997, pp. 15-21.

[41] R. P. M. Bak and E. H. Meesters, "Coral Population Structure: The Hidden Information of Colony Size-Frequency Distributions,” Marine Ecology Progress Series, Vol. 162, 1998, pp. 301-306. doi:10.3354/meps162301

[42] E. H. I. Meesters, M. Hilterman, E. Kardinaal, M. Keetman, M. de Vries and R. P. M. Bak, "Colony Size-Frequency Distributions of Scleractinian Coral Populations: Spatial and Interspecific Variation,” Marine Ecology Progress Series, Vol. 209, 2001, pp. 43-54.

[43] S. S. Oigman-Pszczol and J. C. Creed, "Size Structure and Spatial Distribution of the Corals Mussismilia hispida and Siderastrea stellata (Scleractinia) at Armação Dos Búzios, Brazil,” Bulletin of Marine Science, Vol. 74, No. 2, 2004, pp. 433-448.

[44] M. J. C. Crabbe, "Scleractinian Coral Population Size Structures and Growth Rates Indicate Coral Resilience on the Fringing Reefs of North Jamaica," Marine Environmental Research, Vol. 67, No. 4-5, 2009, pp. 189-198. doi:10.1016/j.marenvres.2009.01.003

[45] D. M. Thompson and R. van Woesik, "Corals Escape Bleaching in Regions That Recently and Historically Experienced Frequent Thermal Stress," Proceedings of the Royal Society B: Biological Science, Vol. 276, No. 1669, 1 January 2009, pp. 2893-2902.

[46] M. J. Crabbe, “Topography and Spatial Arrangement of Reef-Building Corals on the Fringing Reefs of North Jamaica May Influence Their Response to Disturbance from Bleaching," Marine Environmental Research, Vol. 69, No. 3, 2010, pp. 158-162.

[47] J. A. Idjadi, S. C. Lee, J. F. Bruno, W. F. Precht, L. Allen-Requa and P. J. Edmunds, "Rapid Phase-Shift Reversal on a Jamaican Coral Reef," Coral Reefs, Vol. 25, 2006, pp. 209-211. doi:10.1007/s00338-006-0088-7

[48] Y. Loya, "Skeletal Regeneration in a Red Sea Scleractinian Coral Population,” Nature, Vol. 261, 1976, pp. 490491. doi:10.1038/261490a0

[49] J. H. Connell, "Diversity in Tropical Rain Forests and Coral Reefs,” Science, Vol. 199, No. 4335, 1978, pp. 1302-1310. doi: 10.1126/science.199.4335.1302

[50] A. M. Greenaway and D.-A. Gordon-Smith, "The Effects of Rainfall on the Distribution of Inorganic Nitrogen and Phosphorus in Discovery Bay, Jamaica,” Limnology and Oceanography, Vol. 51, No. 5, 2006, pp. 2206-2220.

[51] K. G. Howard, B. D. Schumacher and J. D. Parrish, “Community Structure and Habitat associations of Parrotfishes on Oahu, Hawaii,” Environmental Biology of Fishes, Vol. 85, No. 2, 2009, pp. 175-186. doi: 10.1007/s10641-009-9478-3

[52] D. C. Dunnand and P. N. Halpin, "Rugosity-Based Regional Modelling of Hard-Bottom Habitat," Marine Ecology Progress Series, Vol. 377, 2009, pp. 1-11. 
doi: 10.3354/meps07839

[53] K. R. N. Anthony, D. I. Kline, G. Diaz-Pulido, S. Dove and O. Hoegh-Guldberg, "Ocean Acidification Causes Bleaching and Productivity Loss in Coral Reef Builders," Proceedings of the National Academy of Sciences USA, Vol. 105, No. 45, 2008, pp. 17442-17446.

doi: $10.1073 /$ pnas.0804478105

[54] A. P. Kinzig, P. Ryan, M. Etienne, H. Allison, T. Elm- qvistand and B. H. Walker, "Resilience and Regime Shifts: Assessing Cascading Effects,” Ecology and Society, Vol. 11, No. 1, 2006, Article ID: 20.

[55] M. A. Brockhurst, N. Colegrave, D. J. Hodgsonand and A. Buckling, "Niche Occupation Limits Adaptive Radiation in Experimental Microcosms," PLoS One, Vol. 2, No. 2, 2007, Article ID: e193.

doi: 10.1371/journal.pone.0000193 